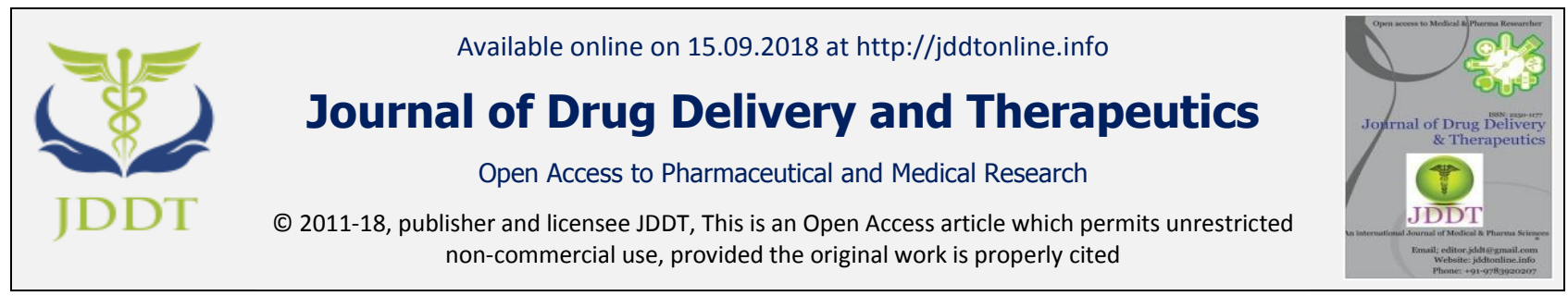

Open ${ }_{\text {Access }}$

Research Article

\title{
RANDOMISED DOUBLE-BLIND PLACEBO-CONTROLLED STUDY OF FOLIC ACID ADJUNCT FOR 8 WEEKS IN HYPERHOMOCYSTEINAEMIC HYPERTENSIVE PATIENTS IN ZARIA, NIGERIA *ONYEMELUKWE Obiageli $\mathrm{U}^{\text {a, b}}$; MAIHA Bilkisu B ${ }^{\text {b; }}$ AYANWUYI Lydia $\mathrm{O}^{\text {b; }}$ DAHIRU Tukur ${ }^{\text {c }}$ \\ ${ }^{a}$ Department of Medicine, Ahmadu Bello University Teaching Hospital, Zaria, Nigeria \\ ${ }^{\mathrm{b}}$ Department of Pharmacology and Therapeutics, Faculty of Pharmaceutical Sciences, Ahmadu Bello University, Zaria, Nigeria \\ ${ }^{\mathrm{c}}$ Department of Community Medicine, Faculty of Medicine, Ahmadu Bello University, Zaria, Nigeria.
}

\begin{abstract}
Objectives: This study was aimed at determining the effect of folic acid adjunct therapy on homocysteine (HCY) and blood pressure (BP) levels in hypertensive subjects.

Method: The study was a double blind placebo-controlled trial on 100 hypertensive patients randomised into 50 folate and 50 placebo groups, where the folate group had $5 \mathrm{mg}$ folic acid daily for 8 weeks. Fasting plasma homocysteine, folate and blood pressure levels were determined at baseline, at 4 and at 8 weeks. The Mixed Model Repeated Measures analysis of variance was applied for data analysis.

Results: Hyperhomocysteinaemia was found at baseline in the folate $(21.3 \pm 5.7 \mu \mathrm{mol} / \mathrm{L})$ and placebo $(21.6 \pm 4.9 \mu \mathrm{mol} / \mathrm{L})$ groups which did not differ statistically $(p>0.05)$. Folic acid adjunct therapy, reduced homocysteine levels at 4 weeks by $2.0 \mu \mathrm{mol} / \mathrm{L}(9.2$ $\%, p<0.05)$ and at 8 weeks by $1.2 \mu \mathrm{mol} / \mathrm{L}(5.6 \%, p<0.05)$, with no significant $(p>0.05)$ systolic and diastolic blood pressure lowering effect. High base-line folate levels were found in both folate $(113.8 \pm 51.2 \mathrm{ng} / \mathrm{ml})$ and placebo groups $(109.5 \pm 51.4 \mathrm{ng} / \mathrm{ml})$ with no statistically significant difference $(p>0.05)$.

Conclusion: Short-term daily folic acid supplementation over 8 weeks had a significant homocysteine reduction effect with no significant reduction in systolic and diastolic blood pressures of hypertensive subjects in Zaria, Nigeria. Hyperhomocysteinaemia could not be accounted for by suboptimal folate levels.
\end{abstract}

Keywords: Hypertension, Homocysteine, Blood pressure, Folate, Placebo, Nigeria.

Abbreviations: Hcy, Homocysteine; BP, Blood Pressure; MTHF, MethylTetraHydroFolate; FA/VB ${ }_{9}$, Folic acid/ Vitamin B 9.

Article Info: Received 26 July, 2018; Review Completed 19 Aug 2018; Accepted 25 Aug 2018; Available online 15 Sep 2018

\section{Cite this article as:}

Onyemelukwe OU, Maiha BB, Ayanwuyi LO, Dahiru T, Randomised double-blind placebo-controlled study of folic acid adjunct for 8 weeks in hyperhomocysteinaemic hypertensive patients in Zaria, Nigeria, Journal of Drug Delivery and Therapeutics. 2018; 8(5):338-348 DOI: http://dx.doi.org/10.22270/iddt.v8i5.1879

\section{*Address for Correspondence:}

ONYEMELUKWE Obiageli Uzoamaka, Department of Medicine, Ahmadu Bello University Teaching Hospital, Shika, Zaria, Nigeria. Tel: +234 8129930000;

\section{INTRODUCTION}

Hypertension prevalence is rapidly rising globally and it is expected that by the year 2025, 1.56 billion adults will be living with hypertension worldwide. ${ }^{1,2}$ In some African settings, it is rated $40 \%^{2}$ while surveys in Nigeria reveal ranges between $22.5 \%-28 \%$. ${ }^{3}$ This rising trend in Africa has been linked to epidemiologic transition, westernisation, and lifestyle changes of Africans, such as smoking, alcoholism, obesity, sedentary lifestyle, and poor diets high in salt, low in fibre, fruits as well as vegetables. ${ }^{2}$

These risk factors of hypertension cannot totally explain the increased predisposition to hypertensive complications like stroke, heart failure or heart attack. ${ }^{4}$ Consequently, there are other emerging risk factors, one 
of which hyperhomocysteinaemia has gained prominent focus in the past few decades. ${ }^{4}$

Homocysteine is a sulphur containing amino acid, a derivative of the metabolism of the essential amino acid, methionine obtained from dietary protein like meat, sea foods, eggs, and dairy products.

Hyperhomocysteinaemia occurs when plasma homocysteine level is greater than $15 \mu \mathrm{mol} / \mathrm{L}^{5-6}$ with normal range between 5-15 $\mu \mathrm{mol} / \mathrm{L} .{ }^{7-8}$ It is metabolised via two major pathways: a remethylation pathway and a trans-sulphuration pathway ${ }^{9}$. Vitamin cofactors such as vitamin $\mathrm{B}_{12}$, folic acid, vitamin $\mathrm{B}_{6}$ and betaine are required in these metabolic processes. ${ }^{7,9}$ Consequently, deficiencies in these required cofactors or inherited deficiency or mutation in enzymes like cystathionine synthase and 5-methyl tetrahydrofolate reductase enzyme (MTHFR) necessary for metabolism of homocysteine, will lead to increased blood levels of homocysteine. ${ }^{6-7,9-10}$ Hyperhomocysteinaemia has been found to result in widespread endothelial damage that manifests clinically with a raised blood pressure. ${ }^{11}$

The mechanisms linking hyperhomocysteinaemia and high blood pressure are attributed to direct endothelial injury on account of the following findings: elevated asymmetric dimethylarginine and reactive oxygen species; decreased nitric oxide bioavailability and generation of peroxynitrite (a strong oxidant that leads to nucleic acid and protein oxidation, lipid peroxidation, and inactivation of enzymes which cause necrosis and apoptosis of cells). ${ }^{9,}{ }^{12-13}$ Furthermore, altered DNA methylation, gene expression and smooth muscle proliferation, as well as activated transcription factors e.g. nuclear factor kappa- $\beta$ (NFk- $\beta$ ) responsible for activation of inflammatory molecules (chemokines, cytokines, monocyte chemoattractant protein-1 (MCP-1) and interleukins) are also involved. ${ }^{9,12-13}$ All these lead to endothelial injury, platelet aggregation, thrombi formation, smooth muscle proliferation, collagen deposition, oxidation of low density lipoprotein cholesterol (LDL-C) and damage to elastin fibres resulting in atherosclerosis. ${ }^{9,12}$

Studies have shown that hyperhomocysteinaemia is prevalent even in normal healthy Nigerians but with few studies done in hypertensive Nigerian subjects. ${ }^{7,14-15}$ Hyperhomocysteinaemia has also been attributed to the possibility of inadequate dietary folate intake worldwide and in sub-Saharan Africa. ${ }^{16-18}$ It has also been shown that simple, inexpensive, non-toxic therapy with vitamins $\mathrm{B}_{2}, \mathrm{~B}_{6}, \mathrm{~B}_{9}$ (folate) and $\mathrm{B}_{12}$, is therapeutically effective at reducing plasma homocysteine levels with maximal effect within 2-6 weeks of therapy ${ }^{4,6}$. Some other study using folic acid alone, showed no significant difference $(p=0.48)$ from using combination of the $\mathrm{B}$ vitamins ${ }^{19}$, however with varying degrees of homocysteine reduction in the different studies. ${ }^{19-20}$ The effect of folic acid with or without other B vitamins on blood pressure has yielded conflicting findings. While some studies done elsewhere but not in Nigeria reported no blood pressure reduction effect, ${ }^{20-22}$ another study showed systolic (SBP) but not diastolic blood pressure (DBP) reduction effect, ${ }^{23}$ and yet some other study showed reduction in both systolic and diastolic blood pressures. ${ }^{6}$ There is a paucity of data regarding the effect of folic acid adjunct therapy in hypertensive patients in Nigeria, thus noting that there are racial and geographic differences worldwide. The present study may become imperative to determine if folic acid can be used as an adjunct in the treatment of hypertension in Nigerian Africans.

The present study was therefore aimed at investigating the effect of short-term folic acid supplementation on plasma homocysteine and blood pressure levels in hypertensive patients in Zaria, Nigeria. Furthermore, it was also aimed at determining plasma homocysteine, blood pressure and folate levels at base-line, 4 weeks and 8 weeks in: hypertensive patients on folic acid intervention and hypertensive controls on placebo.

\section{METHODS}

\section{Research Design and Study Location}

It was a double-blinded placebo-controlled experimental study, which was carried out among Hypertensive subjects seen at the Outpatient Department (OPD) of the Ahmadu Bello University (ABU) Medical Center, Zaria from January, 2016 to June, 2016. Other study locations were the Immunology Laboratory and Chemical Pathology Laboratory of Ahmadu Bello University Teaching Hospital, Zaria where laboratory analysis were carried out.

Ethical clearance was obtained from the Health Research Ethical Committee, Ministry of Health, Kaduna with HREC number: MOH/ADM/744/VOL.1/369 and all participants gave written informed consent.

Sampling Technique: A total of 100 patients were enrolled prospectively and randomly assigned by block randomisation of five to either hypertensive treatment (50 patients) and hypertensive placebo (50 patients) groups by a trained research assistant (a pharmacist).

\section{Inclusion and Exclusion Criteria:}

Inclusion criteria were adult subjects with willingness to participate, prior physician diagnosis of hypertension (BP $\geq 140 / 90 \mathrm{mmHg}$ ), current use of antihypertensive medications and non-diabetics (Fasting blood glucose < $7 \mathrm{mmol} / \mathrm{L}$ ). Exclusion criteria were patients with renal failure (serum creatinine $>3 \mathrm{~g} / \mathrm{dl}$ or GFR $<60 \mathrm{ml} / \mathrm{min}$ as determined by Cockcroft-Gault equation; ${ }^{24}$ current tobacco use; excessive alcohol use and caffeine use; chronic folic acid, vitamin $\mathrm{B}_{12}$ and vitamin $\mathrm{B}_{6}$ supplementation; history of heart failure, stroke, heart attack, sickle cell disease or pregnancy; drugs such as methotrexate, anticonvulsants, nitrous oxide, sulfadoxine-pyrimethamine, penicillamine and failure to adhere strictly to protocol or failure to follow up.

Screening Evaluation: A total of 140 hypertensive patients were screened at the Ahmadu Bello University Medical Center. There were 34 who did not meet eligibility criteria on account of current tobacco use, excess alcohol intake, current vitamin supplementation and febrile illness on sufadoxine-pyrimethamine therapy, diabetes and obesity. The remaining 106 patients met eligibility criteria, out of which 6 were excluded: 2 on account of previous stroke; 2 due to 
hypertensive heart failure and 2 newly diagnosed hypertensive patients not on anti-hypertensive therapy. Consequently, there were a total of 100 hypertensive patients randomised by blocks of 5 into folic acid intervention group and placebo group by a trained pharmacist, so that a total of 50 folic acid and 50 placebo groups were obtained.

Data Collection: This was done by the lead author and 4 trained assisting medical doctors via a well-structured interviewer-administered questionnaire obtained from all screened patients. The most important data obtained during the screening included, bio-data (address, age, sex, tribe, religion); establishment of hypertension and duration of hypertension; drug treatment of hypertension; detailed 24 hour dietary recall; family and social history. Physical examination, anthropometric measurements (weight, height \& body mass index in $\mathrm{kg} / \mathrm{m}^{2}$ ), and blood pressure, were determined at first contact (week 0), weeks 4 and 8. Blood sampling for plasma homocysteine and folate levels were done on weeks 0,4 and 8 .

Blood Sampling: Blood sample $(10 \mathrm{ml})$ was collected from the antecubital vein of either arms, following an overnight fast and without tourniquet application. The blood was divided into two $5 \mathrm{ml}$ aliquots. This was put into labelled potassium EDTA-containing plastic lavender vacutainer tubes in which a drop of aprotinin $\left(\right.$ Trasylol ${ }^{\circledR}$ ) $0.6 \mathrm{TIU} / \mathrm{ml}$ or 500 Kallikrein inactivator $\mathrm{U} / \mathrm{ml}$ had been added, as well as plain specimen bottles respectively. Aprotinin was to inhibit the activity of proteinases and enhance stability of homocysteine or folate in plasma. The test tubes were taken to the Immunology laboratory of ABUTH, Zaria within 4 hours of collection in ice cubes, where they were centrifuged at $1800 \mathrm{rpm}$ for 20 minutes. The plasma was separated within one to two hours and divided into aliquots in cryovials and stored at $-70{ }^{\circ} \mathrm{C}$ until assay. Baseline investigations such as serum electrolyte, urea and creatinine and fasting blood glucose, were also assayed in the Chemical Pathology Laboratory of the ABUTH, Zaria using the Chenray 120 automated clinical chemistry auto-analyser.

Measurement of Plasma Homocysteine and Folate Levels: Laboratory analysis was by laboratory scientist in 2 batches under the same prevailing condition of storage and in the presence of the lead author. The Human direct homocysteine enzyme linked immunosorbent assay kit (ELISA-Elabscience Biotechnology Co., Ltd., WuHan, P.R.C. with Lot No: AK0016JULI5066 and Catalog No: E-EL-HO156), was used for in-vitro quantitative determination of human homocysteine in plasma with detection range of 0.63-40 $\mathrm{pmol} / \mathrm{mL}$ equivalent to $0.63-40 \mu \mathrm{mol} / \mathrm{L}$ and based on manufacturer's manual and according to the ELISA technique described by Frantzen et al. ${ }^{25}$ The folic acid ELISA kit (Elabscience Biotechnology Co. Ltd., WuHan, P.R.C. with Lot No: AK0016JULI5067 and
Catalog No: E-EL-0009), was used for the in-vitro quantitative determination of plasma folate levels, with detection range of $12.5-800 \mathrm{ng} / \mathrm{mL}$.

Treatment and Concomitant treatment: Those in the folate group were given a 4 week supply of pills and instructions on pill-taking, daily $5 \mathrm{mg}$ folic acid while, those in the placebo group were given same supply of its matching placebo, which looked similar to folic acid in shape, smell and size but were devoid of the folic acid active ingredient. Participants remained on the same daily dose throughout the entire study for 8 weeks in addition to their standard anti-hypertensive therapy (calcium channel blockers, ACE inhibitors, Angiotensin II receptor blockers, diuretics and beta-blockers as the case may be). The patients, physicians, and all members of the research team as well as the lead author except the pharmacist, were all blinded to the randomisation procedure and treatment assignments from the beginning till the end of the study. Patients were encouraged to return to the hospital for follow up visits every 4 weeks. Participant compliance to therapy was also measured by pill count. Blood folate levels were determined as a marker of folic acid intake. Extensive health talks were given to the subjects on drug compliance and lifestyle modification by the lead author, the nurses and pharmacist. Provision was made ahead of time to locate patients at home if they did not attend clinic as scheduled and two weekly reminders on pill compliance were sent to each subject by text messages on their mobile telephones. Patients who failed to appear on weeks 4 and 8 of the treatment, despite all attempts to locate them were withdrawn from the study.

Data Analysis: Data was validated and analysed by SPSS version-16 software (SPSS, Inc., Chicago, IL, USA). Data was presented as mean \pm SD for parametric data. Difference between the 2 groups was determined by Chi square analysis for non-numerical variables and student's t - test for numerical variables. Mixed model repeated measures analysis of variance (ANOVA) with post-hoc Bonferroni and Parameter estimates was used to compare folate, homocysteine and blood pressure levels in intervention and placebo groups at week 0,4 and 8. Partition limit for homocysteine was $15 \mu \mathrm{mol} / \mathrm{L}$ and that for folate was $20 \mathrm{ng} / \mathrm{mL}$. Level of significance was assumed to be $p<0.05$ at $95 \%$ confidence interval.

\section{RESULTS}

Group Profile: Out of the 100 hypertensive patients that were enrolled, 14 were withdrawn prior to completion of the study. There were 12 patients who were lost to follow up by week $4 ; 7$ in the intervention group and 5 in the placebo group while 2 patients withdrew their consent from the placebo group by week 8 (Figure 1). The remaining 86 hypertensive patients consisted of 43 subjects in each group that completed the study (Figure 1). 


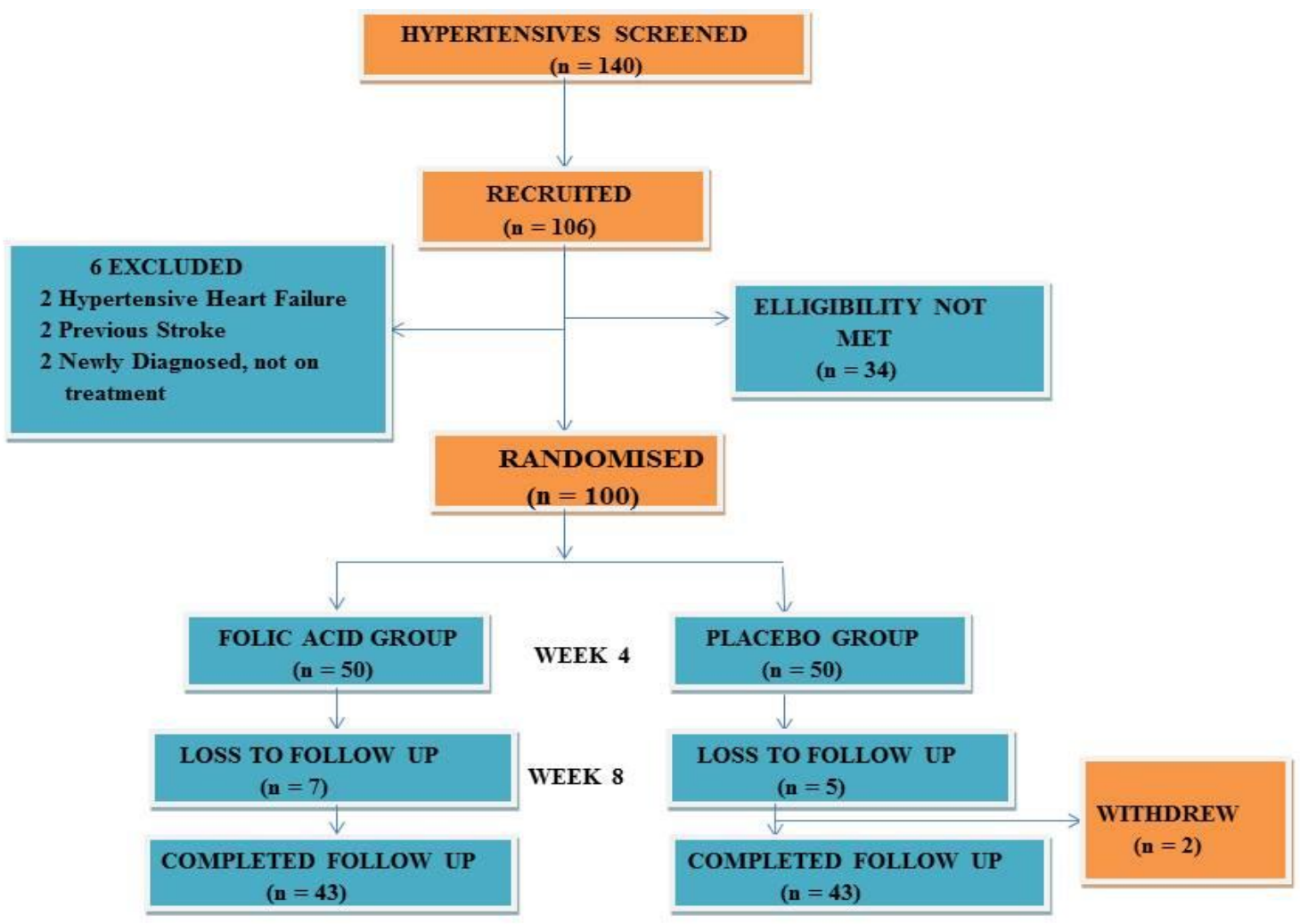

Figure 1: Flow Chart of an 8-week Folic Acid Supplementation among Hypertensive Adults in ABU Medical Centre, Main Campus, Zaria, Nigeria. (2016).

Socio-Demographic Findings: The baseline sociodemographic data were not significantly different between the folic acid and placebo groups with respect to the age, sex, tribe, and educational status $(p>0.05)$ (Table 1). The mean age of the folic acid group was $50.4 \pm 10.2$ years, similar to that of the placebo group
$(51.0 \pm 9.4$ years $)(p=0.97)$. There were $28(65.1 \%)$ females in the folic acid group $(p=0.65)$, similar to the placebo group, $29(67.4 \%)$. There was also no significant difference $(p=0.65)$ in the number of males in both the folic acid $(15,34.9 \%)$ and placebo groups $(14,32.6 \%)$ respectively (Table 1$)$.

Table 1: Base-line Socio-demographic Characteristics of the Study Subjects

\begin{tabular}{lccc}
\hline Variables & $\begin{array}{c}\text { Folic Acid } \\
(\mathbf{n}=\mathbf{4 3})\end{array}$ & $\begin{array}{c}\text { Treatment } \\
(\mathbf{n}=\mathbf{4 3})\end{array}$ & P-value \\
\hline Age & $50.4 \pm 10.2$ & $51.0 \pm 9.4$ & \\
30-44 years & $13(30.2 \%)$ & $14(32.6 \%)$ & 0.97 \\
$45-64$ years & $27(62.8 \%)$ & $26(60.5 \%)$ & \\
$>$ 65 years & $3(7.0 \%)$ & $3(7.0 \%)$ & 0.65 \\
Sex & & & \\
Male & $15(34.9 \%)$ & $14(32.6 \%)$ & \\
Female & $28(65.1 \%)$ & $29(67.4 \%)$ & \\
Tribe & & & \\
Hausa & $21(48.8 \%)$ & $24(55.8 \%)$ & \\
Igbo & $4(9.3 \%)$ & $4(9.3 \%)$ & \\
Yoruba & $3(7.0 \%)$ & $5(11.6 \%)$ & \\
Minority & $15(34.9 \%)$ & $10(23.3 \%)$ & \\
Educational level & & & \\
None & $12(27.9 \%)$ & $12(27.9 \%)$ & \\
Primary & $6(14.0 \%)$ & $16(37.2 \%)$ & \\
Secondary & $10(23.3 \%)$ & $8(11.6 \%)$ & \\
Tertiary & $8(18.6 \%)$ & $2(4.7 \%)$ & \\
Post graduate & $8(18.6 \%)$ &
\end{tabular}

Data are presented as mean $\pm \mathrm{SD}$

Difference between Folic Acid and Placebo by Chi square analysis for non-numerical variables and student $\mathrm{t}$ - test for numerical variables, $* p<0.05$ is the level of significance. 
Clinical and Laboratory Findings: The baseline clinical and laboratory parameters of the study subjects did not differ significantly ( $p>0.05$ ) (Table 2$)$. The mean \pm SD systolic blood pressure in the folic acid group was $144.70 \pm 20.7 \mathrm{mmHg}$ which did not differ statistically ( $p$ $=0.57)$, from that of the placebo group $(142.3 \pm 18.1$ $\mathrm{mmHg}$ ). The mean $\pm \mathrm{SD}$ diastolic blood pressure of the folic acid group was $89.1 \pm 11.5 \mathrm{mmHg}$ with no statistically significant difference $(p=0.60)$, with that of the placebo group $(90.5 \pm 12.9 \mathrm{mmHg})$. The Body mass index, vegetables and fruits in daily diet, duration of hypertension, family history of hypertension and antihypertensive drug therapy between the two groups also did not differ significantly $(p>0.05)$ (Table 2$)$.
The base-line folate $(p=0.86)$ and homocysteine concentrations $(p=0.81)$ were not significantly different between the two groups $(p>0.05)$ (Table 2$)$. The baseline mean homocysteine levels in both folic acid $(21.3 \pm$ $5.7 \mu \mathrm{mol} / \mathrm{L})$ and placebo $(21.6 \pm 4.9 \mu \mathrm{mol} / \mathrm{L})$ groups were found to be higher than normal $(15 \mu \mathrm{mol} / \mathrm{L})$. The base-line mean folate levels were also high in both the folic acid $(112.5 \pm 52.1 \mathrm{ng} / \mathrm{mL})$ and placebo $(110.6 \pm$ $51.2 \mathrm{ng} / \mathrm{mL})$ groups $(20 \mathrm{ng} / \mathrm{mL})$. The Glomerular filtration rate (GFR), packed cell volume (PCV) and fasting blood glucose (FBG) were within normal limits in both groups and had no statistically significant difference $(p>0.05)$ (Table 2).

Table 2: Base-line Clinical and Laboratory Parameters of Study Subjects

\begin{tabular}{|c|c|c|c|}
\hline Variables & $\begin{array}{l}\text { Folic Acid } \\
\quad(n=43)\end{array}$ & $\begin{array}{l}\text { Placebo } \\
(n=43)\end{array}$ & P-value \\
\hline Body Mass Index $\left(\mathrm{kg} / \mathrm{m}^{2}\right)$ & $27.22 \pm 3.9$ & $26.85 \pm 4.9$ & 0.70 \\
\hline Systolic Blood Pressure (mmHg) & $144.70 \pm 20.7$ & $142.3 \pm 18.1$ & 0.57 \\
\hline Diastolic Blood Pressure (mmHg) & $89.1 \pm 11.5$ & $90.5 \pm 12.9$ & 0.60 \\
\hline Vegetables/Fruits in Daily Diet & $24(55.9 \%)$ & $24(55.9 \%)$ & 1.00 \\
\hline Family History of Hypertension & $25(58.1 \%)$ & $19(44.2 \%)$ & 0.20 \\
\hline \multicolumn{4}{|l|}{ Duration of Hypertension (Years) } \\
\hline$<5$ & $24(55.8 \%)$ & $25(58.1 \%)$ & \\
\hline $6-10$ & $11(25.6 \%)$ & $5(11.6 \%)$ & \\
\hline 11-15 & $5(11.6 \%)$ & $8(18.6 \%)$ & 0.48 \\
\hline $16-20$ & $1(2.3 \%)$ & $2(4.7 \%)$ & \\
\hline$>21$ & $2(4.7 \%)$ & $3(7.0 \%)$ & \\
\hline \multicolumn{4}{|l|}{ Drug History (Years) } \\
\hline$<5$ & $29(67.4 \%)$ & $30(69.8 \%)$ & \\
\hline $6-10$ & $7(16.3 \%)$ & $3(7.0 \%)$ & \\
\hline $11-15$ & $7(16.3 \%)$ & $7(16.3 \%)$ & 0.36 \\
\hline $16-20$ & $0(0.0 \%)$ & $2(4.7 \%)$ & \\
\hline$>21$ & $0(0.0 \%)$ & $1(2.3 \%)$ & \\
\hline \multicolumn{4}{|l|}{ Drug Class } \\
\hline ARB / ACEI & $21(48.84 \%)$ & $18(41.86 \%)$ & \\
\hline Beta Blockers & $4(9.30 \%)$ & $11(25.58 \%)$ & \\
\hline Calcium Channel Blocker & $16(37.21 \%)$ & $15(34.88 \%)$ & \\
\hline Diuretic & $20(46.51 \%)$ & $16(37.21 \%)$ & \\
\hline Centrally Acting Antihypertensive & $1(2.33 \%)$ & $2(4.65 \%)$ & \\
\hline Folate $(\mathrm{ng} / \mathrm{ml})$ & $112.5 \pm 52.1$ & $110.6 \pm 51.2$ & 0.86 \\
\hline Homocysteine $(\mu \mathrm{mol} / \mathrm{L})$ & $21.3 \pm 5.7$ & $21.6 \pm 4.9$ & 0.81 \\
\hline Creatinine $(\mu \mathrm{mol} / \mathrm{L})$ & $68.4 \pm 13.1$ & $70.8 \pm 11.4$ & 0.37 \\
\hline Glomerular Filtration Rate $\left(\mathrm{mL} / \mathrm{min} / 1.73 \mathrm{~m}^{2}\right)$ & $102.5 \pm 14.5$ & $100.8 \pm 13.5$ & 0.56 \\
\hline Packed Cell Volume (\%) & $39.9 \pm 4.4$ & $40.0 \pm 4.8$ & 0.93 \\
\hline Fasting Blood Glucose $(\mathrm{mmol} / \mathrm{L})$ & $5.8 \pm 1.2$ & $5.7 \pm 0.9$ & 0.89 \\
\hline
\end{tabular}

Data are presented as mean \pm SD

Difference between Folic acid and Placebo Groups; Chi square done for categorical variables while student's t-test for numerical variables:

$p<0.05$ is the level of significance; $p>0.05$ is non-significant. ARB/ACEI: Angiotensin II Receptor Blocker/Angiotensin Converting Enzyme Inhibitor.

Plasma Folate Levels: The mean plasma folate levels in the intervention group at weeks 0,4 and 8 were, $113.8 \pm 51.2 \mathrm{ng} / \mathrm{ml}, 144.3 \pm 50.7 \mathrm{ng} / \mathrm{ml}$ and $160.7 \pm 65.2$ $\mathrm{ng} / \mathrm{ml}$ respectively while those of the placebo group were $109.5 \pm 51.4 \mathrm{ng} / \mathrm{ml}, 141.0 \pm 50.1 \mathrm{ng} / \mathrm{ml}$ and 142.7 $\pm 73.9 \mathrm{ng} / \mathrm{ml}$, respectively (Figure 2). There was a statistically significant $(p<0.001)$, difference in timelines between weeks 0 and 4 with regards to plasma folate concentrations as well as weeks 0 and 8 (Figure 2). 


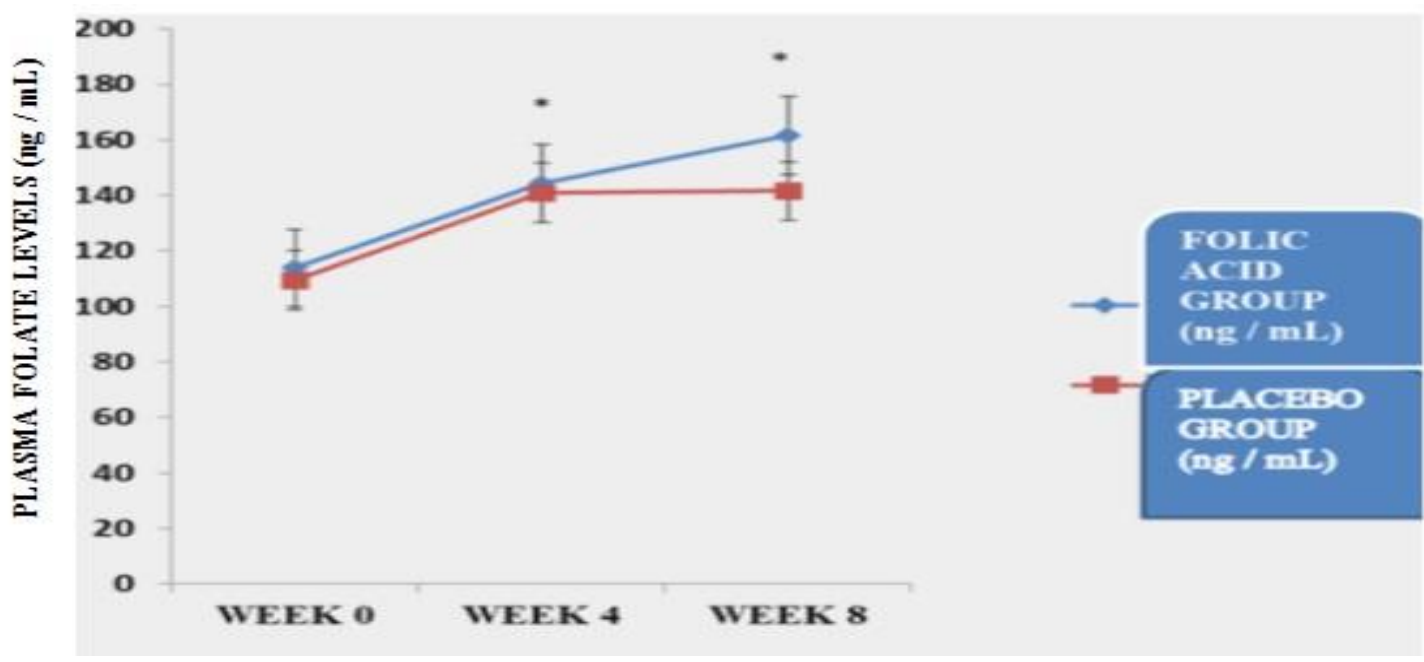

Figure 2: Plasma Folate Levels Between Folate and Placebo Groups over 8 Weeks $(n=43)$

Mixed model repeated measures ANOVA with post-hoc Bonferroni. *Mean difference between Folic acid and Placebo groups at week 0 and 4 as well as week 0 and 8 , significant at $p<0.001$.

Plasma Homocysteine Levels: The mean plasma homocysteine levels in the folic acid group at weeks 0,4 and 8 were as in Table 3 . There was a statistically significant $(p=0.005)$, difference in mean plasma homocysteine levels in the folic acid group when compared to the placebo group between weeks 0 and 4 as well as weeks 0 and 8 by mixed model repeated measures ANOVA with post-hoc Bonferroni test (Table $3)$.

Blood Pressures Levels: Similarly, there was a significant difference in systolic $(p=0.007)$ and diastolic $(p<0.001)$ blood pressures in the folic acid group when compared to the placebo group between weeks 0 and 4 as well as weeks 0 and 8 respectively (Table 3 ).

Table 3: Difference Between Folic Acid Intervention and Placebo Groups with Regards Plasma Folate, Homocysteine and Blood Pressure Levels Between Week 0 and After 4 and 8 Weeks of 5 mg Folic acid Supplementation In Hypertensive Subjects

\begin{tabular}{|c|c|c|c|c|c|}
\hline VARIABLES & TREATMENT & WEEK 0 & WEEK 4 & WEEK 8 & P - Value \\
\hline \multirow[t]{2}{*}{$\begin{array}{l}\text { Plasma Folate } \\
(\mathrm{ng} / \mathrm{ml})\end{array}$} & Intervention $^{a}$ & $113.8 \pm 51.2 * \dagger$ & $144.3 \pm 50.7^{*}$ & $160.7 \pm 65.2 \dagger$ & $<0.001$ \\
\hline & Placebo $^{b}$ & $109.5 \pm 51.4 * \dagger$ & $141.0 \pm 50.1^{*}$ & $142.7 \pm 73.9 \dagger$ & \\
\hline \multirow[t]{2}{*}{$\begin{array}{l}\text { Homocysteine } \\
(\mu \mathrm{mol} / \mathrm{l})\end{array}$} & Intervention ${ }^{a}$ & $21.3 \pm 5.7 * \dagger$ & $20.2 \pm 3.5^{*}$ & $21.9 \pm 2.6 \dagger$ & 0.005 \\
\hline & Placebo $^{b}$ & $21.6 \pm 4.9^{* \dagger}$ & $22.1 \pm 4.6^{*}$ & $23.2 \pm 2.2 \dagger$ & \\
\hline \multirow{2}{*}{$\begin{array}{l}\text { Systolic Blood } \\
\text { Pressure(mmH } \\
\text { g) }\end{array}$} & Intervention ${ }^{\mathrm{a}}$ & $145.6 \pm 20.7 * \dagger$ & $137.8 \pm 15.9^{*}$ & $134.2 \pm 17.4 \dagger$ & 0.007 \\
\hline & Placebo $^{b}$ & $142.8 \pm 18.8 * \dagger$ & $142.4 \pm 15.3^{*}$ & $136.8 \pm 16.9 \dagger$ & \\
\hline \multirow{2}{*}{$\begin{array}{l}\text { Diastolic Blood } \\
\text { Pressure } \\
\text { (mmHg) }\end{array}$} & Intervention ${ }^{\mathrm{a}}$ & $89.1 \pm 11.5 * \dagger$ & $86.6 \pm 7.5^{*}$ & $82.8 \pm 8.2 \dagger$ & $<0.001$ \\
\hline & Placebo $^{b}$ & $90.5 \pm 12.9 * \dagger$ & $89.8 \pm 9.4^{*}$ & $84.3 \pm 7.9 \dagger$ & \\
\hline
\end{tabular}

Data presented as mean \pm SD. Difference between groups $\mathrm{a}$ and $\mathrm{b}$ at weeks 0 and $4\left(^{*}\right)$ and weeks 0 and $8(\dagger)$ by Mixed Model Repeated Measures ANOVA with post-hoc Bonferroni. Mean difference is significant at $p<0.01 ; \mathrm{n}=43$ in each group; a: Folic acid group; b: Placebo group 
Effect of 8 weeks Folic Acid Supplementation on Plasma Homocysteine and Blood Pressure Levels between Folic Acid and Placebo Groups

Plasma Homocysteine Levels: Mixed model repeated measure analysis of variance (ANOVA) with parameter estimates was used to determine the effect of $5 \mathrm{mg}$ folic acid supplementation on plasma homocysteine levels at weeks 4 and 8 . The between-subjects effect showed that the folic acid group had a statistically significant decrease in plasma homocysteine at week $4(\mathrm{~b}=-2.0, p$ $=0.03)$ and week $8(\mathrm{~b}=-1.2, p=0.02)$ from base-line values (Table 4). Hence plasma homocysteine levels reduced by $2 \mu \mathrm{mol} / \mathrm{L}(9.4 \%)$ from base-line values by week 4 and $1.2 \mu \mathrm{mol} / \mathrm{L}$ (5.9\%) from base-line values by week 8 .

Systolic Blood Pressure Levels (SBP): Betweensubjects effects showed that folic acid supplementation had no statistically significant $(p>0.05)$ decrease in SBP at week 4 and week 8 with a decrease of $5.7 \mathrm{mmHg}$ $(3.3 \%)$ and $2.3 \mathrm{mmHg}(1.9 \%)$ respectively (Table 4$)$.

Diastolic blood pressure (DBP): The DBP at 4 and 8 weeks was compared with base-line values to detect between-subjects effects. A decrease of $3.1 \mathrm{mmHg}(3.6$ $\%)$ by week 4 and $1.5 \mathrm{mmHg}(1.8 \%)$ by week 8 were observed but these were not statistically significant $(p>$ 0.05) (Table 4)

Table 4: Effect of Folic Acid (5 mg) Supplementation on Plasma Homocysteine and Blood Pressure Levels in Hypertensive Subjects at Weeks 4 and 8

\begin{tabular}{|c|c|c|c|c|c|c|c|}
\hline \multirow[b]{2}{*}{ Variables } & \multirow[b]{2}{*}{ Treatment } & \multicolumn{3}{|c|}{ Week 4} & \multicolumn{3}{|c|}{ Week 8} \\
\hline & & b & $\mathbf{P}$ & o Reduction & b & $\mathbf{P}$ & $\%$ Reduction \\
\hline $\begin{array}{l}\text { Homocysteine } \\
(\mu \mathrm{mol} / \mathrm{L})\end{array}$ & $\begin{array}{l}\text { Intervention } \\
\text { Placebo }\end{array}$ & -2.0 & $0.03 *$ & -9.4 & -1.2 & $0.02 *$ & -5.9 \\
\hline $\begin{array}{l}\text { Systolic BP } \\
(\mathrm{mmHg})\end{array}$ & $\begin{array}{l}\text { Intervention } \\
\text { Placebo }\end{array}$ & -5.7 & 0.09 & 3.3 & -2.3 & 0.54 & -1.9 \\
\hline $\begin{array}{l}\text { Diastolic BP } \\
(\mathrm{mmHg})\end{array}$ & $\begin{array}{l}\text { Intervention } \\
\text { Placebo }\end{array}$ & -3.1 & 0.09 & 3.6 & -1.5 & 0.39 & -1.8 \\
\hline
\end{tabular}

Interaction between Subjects Factors (Drugs) and Within Subjects Factor (Time) by Mixed Model Repeated Measures ANOVA with Parameter Estimates. b: Effect change. *Mean difference is significant at $p<0.05$ level. $\mathrm{n}=43$ in each group.

\section{DISCUSSION}

Studies are on-going in different parts of the world to determine the role of plasma homocysteine and whether its reduction would help ameliorate the incidence and complications of cardiovascular diseases. ${ }^{6}$ In view of this, we have attempted in this randomised double blind placebo controlled study, to investigate whether folic acid supplementation as an adjunct therapy, would have any lowering effect on homocysteine and blood pressure levels in hypertensive patients in Zaria, Nigeria.

The mean ages of the subjects were within the $5^{\text {th }}$ decade similar to previous studies. ${ }^{6,20,27}$ It however, contrasts reports of other studies ${ }^{21,22,28}$ which involved older adults $\geq 65$ years, as well as the Tehran homocysteine survey ${ }^{23}$, which involved younger adults (mean, $41 \pm 2$ years). The current study had a female preponderance, perhaps due to the health seeking nature of females, similar to the Tehran homocysteine study. ${ }^{23}$ Moreso, there appears to be a gender shift in the global trend of cardiovascular diseases towards females. ${ }^{29}$
Females have also been shown to be predisposed to preeclampsia and hypertension, due to molecular vascular risk factors like soluble endoglins, tyrosine kinase, vascular endothelial growth factor (VEGF) implicated in its causation. ${ }^{30}$

The mean plasma folate levels in the folic acid and placebo groups, were 5 times higher than the upper limit of normal $(2-20 \mathrm{ng} / \mathrm{mL}$ or $4.5-45.3 \mathrm{nmol} / \mathrm{L})$ using the standard reference range for the United States. ${ }^{31}$ This contrasts reports from the United States and European countries where folate levels were reported to range from 9.8-21 nmol/L with median pre-treatment value of $14.2 \mathrm{nmol} / \mathrm{L}$ as reported by the meta-analysis of 25 randomised controlled trials. ${ }^{20}$ Moreso, there has been reports of folate deficiency outside Nigeria ${ }^{18}$ with reference range for Europe being between 3.8-16.0 $\mathrm{ng} / \mathrm{mL}$ and USA between $8.4-35.2 \mathrm{ng} / \mathrm{mL}$, while that for Uganda was $4.17-20 \mathrm{ng} / \mathrm{ml}$. ${ }^{32}$ Research indicates that folate deficiency may be an important cause of hyperhomocysteinaemia in the general population. ${ }^{19,27}$ However, the current study is interesting because it 
shows a contrary result and will guide the noncommunicable disease control efforts in the country not only in determining the real operative risk factors but also to prescribe remedies appropriate to our setting as this study has shown that folate was not deficient.

The high pre-treatment folate levels in our subjects may be attributed firstly to the difference in racial factors which are yet undefined as well as geographical factors especially as the substantial number of hypertensive subjects in both folic acid and placebo groups had vegetables and fruits in their daily diet as vegetables are common in this farming environment. Secondly, the dietary pattern of the inhabitants of the Northern region of Nigeria, where their diet contains rich sources of folate and vitamins obtained from vegetables such as spinach, lettuce, pumpkin, okra, green leafy vegetables, cucumber, carrots and fruits like watermelon which are currently grown extensively in the North and marketed down to the Southern States ${ }^{33-34}$. The Hausas also eat grains, beans, peanuts also in form of "kuli kuli", and milk (in form of "fura da nono") as complementary protein diet which are also rich sources of vitamins and folate. ${ }^{33-34}$

Hyperhomocysteinaemia is defined as total homocysteine $\geq 15 \mu \mathrm{mol} / \mathrm{L}$ with levels of $16-30 \mu \mathrm{mol} / \mathrm{L}$ classified as mild, 31-100 $\mu \mathrm{mol} / \mathrm{L}$ as moderate and > $100 \mu \mathrm{mol} / \mathrm{L}$ as severe hyperhomocysteinaemia. ${ }^{6}$ This study showed high pre-treatment homocysteine levels in hypertensive patients in both groups. This is similar to reports from other parts of Nigeria ${ }^{7,13,15}$ Reports from other countries like Iran, ${ }^{23}$ India ${ }^{6}$ and Italy ${ }^{27}$ showed similar high levels. However, this is contrary to reports from the meta-analysis of 25 randomised controlled trials done in USA and European countries, which showed median pre-treatment homocysteine levels of $10.5 \mu \mathrm{mol} / \mathrm{L} \quad(8.5-13.6 \mu \mathrm{mol} / \mathrm{L}) .{ }^{20}$ The disparity between the current study and that of the USA and European countries may be attributed to racial, ethnic and geographical differences. For instance, studies have shown that there are two types of hyperhomocysteinaemia: firstly, that due to major genetic mutations of the enzymes implicated in homocysteine metabolism such as cystathionine-betasynthase (CBS), methylenetetrahydrofolate reductase (MTHFR), or due to enzymes involved in methyl- $\mathrm{B}_{12}$ synthesis and homocysteine methylation. ${ }^{35-36}$ The latter which is rare, accounts for the severe form of hyperhomocysteinaemia. ${ }^{35-36}$

Secondly, hyperhomocysteinaemia due to socioenvironmental factors like folate, vitamin $\mathrm{B}_{6}$ and $\mathrm{B}_{12}$ deficiencies or genetic factors like thermolabile MTHFR deficiency. The deficiencies in the socio-environmental factors are the more common forms which cause mild to moderately elevated homocysteine levels as observed in this study ${ }^{35-36}$ The base-line hyperhomocysteinaemia may however, not be accounted for by suboptimal folate status, since the folate levels obtained in the present study were well above the reference range for healthy adults in the United States. The plasma vitamin $B_{12}$ and $\mathrm{B}_{6}$ levels were not determined in the present study hence their deficiencies could not be ascertained as the cause of the high homocysteine levels observed. However, it is pertinent to note that a study by Flemming et al. ${ }^{39}$ showed that vitamin $\mathrm{B}_{12}$ deficiency was rare in Northern Nigerians.

Furthermore, due to lack of facilities for genetic studies in Nigeria, knowledge on genetic aberrations and their polymorphisms are not known, ${ }^{7}$ hence the mild to moderate hyperhomocysteinaemia seen in almost all the 86 subjects in this study cannot be accounted for by genetic polymorphism as proposed in a study done in Gombe town of Nigeria, ${ }^{14}$ as this was not assayed in this study.

Poor dietary intake of vitamin containing foods was proposed to occur in Nigerians from the Northern part of the country as reported in a study by Vanderjagt in 2000. ${ }^{17}$ That study concluded that the adolescent girls in the North were at greater risk of vitamin $B_{12}$ deficiency than folate deficiency, consistent with the fact that their diet was proposed then to have few foods that contained vitamin $B_{12}$. That study however, may not generalize for adult population, as young adolescents were studied and perhaps study of current young adolescents need to be carried out. ${ }^{17}$

Other factors that affect homocysteine levels are alcohol use and smoking. ${ }^{9}$ There was no history of smoking or alcohol intake in any of the subjects in the current study that could have contributed to hyperhomocysteinaemia. Smoking and alcohol consumption have been found to be associated with hyperhomocysteinaemia ${ }^{6,40-41}$. The effect of nicotine and or carbon monoxide (CO) from smoking can suppress vitamin $\mathrm{B}_{6}, \mathrm{~B}_{12}$ and folate levels. $6,40-41$ The renal statuses of all the subjects were within normal as determined by the GFR ${ }^{24}$ hence cannot account for the high base-line homocysteine levels, as impaired renal status has been shown to be associated with hyperhomocysteinaemia. ${ }^{9,42}$

There was evidence of folate intake by the folic acid intervention group as plasma folate levels rose from pretreatment levels by weeks 4 and 8 . There was a statistically significant $(p<0.001)$, difference in timelines between the folic acid intervention group and the placebo group. The initial rise in folate levels in the placebo group despite the absence of intake of folic acid is similar to what was obtained in the Tehran homocysteine survey. ${ }^{23}$ This remains unclear, but may be attributed to a "placebo effect" or an improvement in lifestyle and dietary modification with increased folate consumption in their diet from fruits and vegetables, as folate appears to be the most important dietary determinant of plasma homocysteine. ${ }^{23}$ This dietary modification can be attributed to the extensive health talks given to the hypertensive patients at their base-line visit.

Following supplementation with daily dose of folic acid $(5 \mathrm{mg})$ over a period of 8 weeks in the current study, there was a $9.4 \%$ reduction $(2 \mu \mathrm{mol} / \mathrm{L})$ in plasma homocysteine levels by the $4^{\text {th }}$ week and $5.9 \%$ reduction $(1.2 \mu \mathrm{mol} / \mathrm{L})$ by the $8^{\text {th }}$ week. This was consistent with previous reports, but with varying degrees of reduction ${ }^{6}$. In typical European countries and USA, $0.5-5 \mathrm{mg}$ folic acid daily supplementation was shown to reduce homocysteine levels by a quarter to a 
third $(25 \%)^{20,43}$ One other study showed a $49.9 \%$ reduction of homocysteine levels with vitamin cofactor combination, which was not statistically different from the results of using folic acid alone. ${ }^{19}$ The reason for the marginal reduction found in the present study may be attributed to the high pre-treatment folate levels. Research has shown that absolute reductions in blood homocysteine concentrations with folic acid supplementation are greater at higher pre-treatment blood homocysteine concentrations and lower pretreatment folate concentrations. ${ }^{20,44}$ This was not the case with the present study were both the pre-treatment folate and homocysteine levels were very high even at base-line.

The present study also revealed non-significant reduction of folic acid adjunct therapy of systolic and diastolic blood pressures after 8 weeks. This was similar to the findings of McMahon et al. ${ }^{21}$ and the vitamin intervention for stroke prevention (VISP) trial, ${ }^{22}$ in which folate supplementation, had no effect on both systolic and diastolic blood pressure. The findings of the present study contrasts reports from the meta-analysis of 25 randomised controlled trials in USA and European countries, involving the use of folic acid with or without other B vitamins for a short duration of 2 to 14 weeks. ${ }^{20}$ The National Health and Nutrition Examination Survey (NHANES) study done in the US showed that a one standard deviation increase in red blood cell folate (100 $\mathrm{ng} / \mathrm{ml}$ ) was associated with a $5 \mathrm{mmHg}$ reduction in both diastolic and systolic blood pressures. ${ }^{45}$ It also contrasts reports of the Tehran homocysteine survey, ${ }^{23}$ in which supplementation for 8 weeks significantly $(p<0.001)$, reduced SBP with no significant reduction in DBP. The reason for the disparity in the findings of this study and others may probably be because base-line homocysteine levels were only reduced marginally. In addition, folic acid was not combined with other $\mathrm{B}$ vitamins or therapies like betaine (trimethylglycine) or thiols in the present study which may possibly further explain the non-reduction of blood pressure and marginal homocysteine reduction effect.

\section{CONCLUSION}

In conclusion, the study showed that daily folic acid supplementation of standard anti-hypertensive therapy over 8 weeks, had a significant homocysteine reduction effect with no statistically significant reduction in systolic and diastolic blood pressures in hypertensive subjects in Zaria, Nigeria. Hyperhomocysteinaemia found in the subjects could not be accounted for by suboptimal folate levels as base-line pre-treatment plasma folate levels were high in both hypertensive folic acid and placebo groups.

\section{RECOMMENDATIONS}

Folate adjunct therapy is not recommended in adult Nigerian hypertensives as a bid to control blood pressure except in Nigerian pregnant women and sickle cell disease patients as recommended by the expert committee of Non Communicable Diseases; rather emphasis should be on anti-hypertensive drug adherence and lifestyle modification. Sampling multiple centres across Nigeria and the young and elderly should be carried out to determine whether homocysteine is a risk factor for hypertension and whether folic acid supplementation will produce similar outcome as in this study. Further longitudinal studies should be carried out using combination therapy of folic acid with other Bvitamins, betaine or thiols to determine whether there will be more reduction effect on homocysteine as well as any blood pressure effect. Genetic studies should be undertaken to determine if there is any genetic mutation in the gene encoding 5, 10-methylene tetrahydrofolate reductase (MTHFR) required for homocysteine metabolism in hypertensive Nigerians.

\section{ACKNOWLEGEMENT/ SOURCE (S) OF SUPPORT}

Many thanks to MicroNova Pharmaceuticals Ltd., Nigeria and Emzor Pharmaceutical Industries Limited, Lagos, Nigeria for freewill donation of medications. Special thanks to B. B. Maiha, L. O. Ayanwuyi and T. Dahiru who supervised the project; A. Mohammed and N. H Madugu who ensured the study was carried out at the hospital; G. C. Onyemelukwe (MON) of the expert committee on Non-communicable diseases, Federal Ministry of Health, Abuja, Nigeria, who assisted in review of the final version of the manuscript; I. F. Mudashir who randomised the subjects. Many thanks to doctors: C. Chukwumerije, U. Adamu and A. Khalid; laboratory scientists, L. Okonkwo, Y. Bolaji, N. Gargai, A. Akindaro; the nursing team, T. S. Mohammed and G. T. Alamu; the statisticians, B. Egaji and T. Dahiru as well as all the participants of the study.

Source of Support: Emzor Pharmaceutical Industries Limited, Lagos, Nigeria- Supplied Folic acid and its placebo and Micro Nova Pharmaceuticals Limited, Nigeria- Supplied anti-hypertensive drugs.

Conflict of Interest: NONE disclaimers 


\section{REFERENCES}

1. Kearney PM, Whelton M, Reynolds K, Muntner P, Whelton PK, He J, Global burden of hypertension: analysis of worldwide data. Lancet, 2005; 365:217-223

2. Van de Vijver S, Akinyi H, Oti S, Olajide A, Agyemang $\mathrm{CM}$, Aboderin I et al, Status report on hypertension in Africa-consultative review for the $6^{\text {th }}$ session of the African Union Conference of Ministers of Health on noncommunicable diseases. Pan African Medical Journal, 2013; 16: 38. doi:10.11604/pamj.2013.16.38.3100 PMCID: PMC3932118

3. Adeloye D, Basquill C, Aderemi AV, Thompson JY, Obi FA, An estimate of the prevalence of hypertension in Nigeria: systematic review and meta-analysis. Journal of Hypertension, 2015; 33:230-244.

4. Eikelboom JW, Lonn E, Genest JJ, Hankey G, Yusuf S, Homocysteine and cardiovascular disease: a critical review of the epidemiologic evidence. Annals of Internal Medicine, 1999; 131:363-375

5. Ueland PM, Refsum H, Stabler SP, Malinow MR, Anderson A, Allen R, Total homocysteine in plasma and serum: methods and clinical applications. Clinical Chemistry, 1993; 39:1764-1779

6. Ganeshan S, Karthikumar B A, Renjith AA, Alin B. Effect of folic acid on serum homocysteine levels in patients with cardiovascular diseases (CVD). Journal of Chemical and Pharmaceutical Research, 2014; 6(3):1141-1148

7. Ajuluchukwu J, Oluwatowoju IO, Adebayo K, Onakoya A, Plasma homocysteine in diverse cardiovascular diseases in urban Africans. World Life Science Medical Research, 2011; $1(6): 126$

8. Ubbink JB, Delport R. Reference ranges for homocysteine concentrations. In: Robinson $\mathrm{K}$ (editor). Homocysteine and Vascular Disease: Cleveland USA: Springer, Dordrecht; 2000. P. 41-57.

9. Balakumar P, Singh P, Subrahmanya, SG, Singh M, Hyperhomocysteinemia and cardiovascular disorders: is there a correlation? Trends Medical Research, 2007; 2:160166

10. Ranjith V, Serum Homocysteine Levels in Cerebrovascular Accidents. Dissertation submitted to the Rajiv Gandhi University of Health Sciences, Karnataka, Bangalore in partial fulfilment of the requirement for a degree of Doctor of Medicine in General Medicine. 2011. P. 76.

11. Osunkalu VO, Akanmu AS, Adediran A, Abudu O, Homocysteine levels in Nigerian women with preeclampsia/ecclampsia. Sierra Leone Journal of Biomedical Research, 2009; 1(1):55-60

12. Welch GN, Loscalzo J, Homocysteine and atherothrombosis. New England Journal of Medicine, 1998; 338: 1042-1050

13. Akande AA, Salisu OT, Kolo PM, Plasma total homocysteine (tHcy) Levels in Healthy Nigerian Volunteers. Nigerian Hospital Practice, 2009; 1:3-6.

14. Glew RH, Okolie H, Crossey M, Suberu O, Trujillo M, Pereyra M, Vanderjagt DJ, Serum lipid profiles and homocysteine levels in adults with stroke or myocardial infarction in the town of Gombe in Northern Nigeria. Journal of Health Population Nutrition, 2004; 22(4):341-347

15. Alkali NH, Watt H, Bwala SA, Gadzama A, Association of plasma homocysteine and ischaemic stroke in a Nigerian population. Pakistan Journal of Medical Science, 2006; 22:405-408

16. Ubbink JB, Christianson A, Bester MJ, Van Allen MI, Venter PA, Delpert R, Blom HJ, Folate status, homocysteine metabolism and methylene tetrahydrofolate reductase genotype in rural South African blacks with a history of pregnancy complicated by neural tube defects. Metabolism, $1999 ; 48: 209-274$

17. Vanderjagt DJ, Spelman K, Ambe J, Datta P, Blackwell W, Glew RH, Folate and vitamin $B_{12}$ status of adolescent girls in Northern Nigeria. Journal of National Medical Association, 2000; 92(7):334-340

18. McLean E, de Benoist B, Lindsay HA, Review of the magnitude of folate and vitamin $\mathrm{B}_{12}$ deficiencies worldwide. Food Nutrition Bulletin, 2008; 29(2): 38-51

19. Ubbink JB, Veermaak WJ, vader Merwe A, Becker PJ, Delport $\mathrm{R}$, Portgieter $\mathrm{CH}$, Vitamin requirements for the treatment of hyperhomocysteinaemia in humans. Journal of Nutrition, 1994; 124(10): 1927-1933

20. Clarke R, Frost C, Sherliker P, Lewington S, Collins R, Dose-dependent effect of folic acid on blood concentrations of homocysteine: a meta-analysis of randomised trials, homocysteine lowering trialists collaboration. American Journal of Clinical Nutrition, 2005; 82(4):806-812.

21. McMahon JA, Skeaff CM, Williams SM, Green TJ, Lowering B vitamins has no effect on blood pressure in older adults. Journal of Nutrition, 2007; 137(5):1183-1187

22. Spence DJ, Bang H, Chambless EL, Stampfer JM, Vitamin intervention for stroke prevention trial: An efficacy analysis. Stroke, 2005; 36:2404-2409

23. Sharifi F, Fakhrzadeh H, Mirarefin, M, Pourebrahim R, Nouri M, Forouzanfar MH et al, The effects of high-dose folic acid on blood pressure of hypertensive adults with hyperhomocysteinemia: a randomised double-blind placebo controlled clinical trial (Tehran Homocysteine Survey). Iranian Journal of Diabetes and Lipid Disorders, 2010; 9:1320

24. Cockroft DW and Gault MH, Prediction of creatinine clearance from serum creatinine. Nephron, 1976; 16:31-41

25. Frantzen F, Alfheim I, Faaren AI, Nordhei AK, Enzyme conversion immunoassay for determining total homocysteine in plasma or serum. Clinical Chemistry, 1998; 44(2):311316

26. Manufacturers manual for folate assay: https://www.civicbio.com/product/fa-vb9-folic-acid-vitaminb9-elisa-kit-e-el-0009/

27. Scazzone C, Bono A, Tornese F, Arsena R, Schillaci R, Butera D, Cottone S, Correlation between low folate levels and hyperhomocysteinemia but not vitamin $\mathrm{B}_{12}$ in hypertensive patients. Annals of Clinical Laboratory Science, 2014; 44(3):286-290

28. Sicińska E, Brzozowska A, Roszkowski W, Finglas PM, Supplementation with [6S ]-5-methyltetrahydrofolate or folic acid equally reduces serum homocysteine concentration in older adults. Internet Journal of Food Science and Nutrition, 2017; 0(0):1-10

29. Mozzaffarian D, Benjamin EJ, Gofor AS, American heart association statistics committee and stroke statistics subcommittee. Heart disease and stroke statistics-2015 update: a report from the american heart association. Circulation, $2015 ; 131: 29-32$

30. Marek-Trzonkowska N, Kwieczyńska A, Reiwer-Gostomska M, Koliński T, Molisz A, Siebert J, Arterial hypertension is characterized by imbalance of pro-angiogenic versus antiangiogenic factors. PLoS One, 2015; 10 (5):e0126190. doi: 10.1371/journal.pone.0126190.

31. Fischbash F, Dunning MB. Manual of Laboratory and Diagnostic Tests. Philadelphia: Lippincott William \& Wilkins; 2008 
32. Galukande M, Zambwe J, Fualal J, Baingana R, Gakwaya A, Reference values for serum levels of folic acid and vitamin $B_{12}$ in a young adult Ugandan population. African Health Science, 2011; 11(2):240-243

33. Osondu CK, Nwadike FC, Ijioma JC, Udah SC, Ugboaja CI, Marketing performance of salad vegetables: the case of cabbage marketing in abia state, nigeria. International Journal of Agricultural Science, Research and Technology in Extension and Education Systems, 2014; 4(3):151-162

34. Ezebuiro P. Hausa tribe, language, people, culture, history, religion, food, marriage \{Web Log Comment Answer Africa, 2018; Retrieved from https://answersafrica.com/thisis-everything-youll-love-to-know-about-the-hausa-tribe.html

35. Brustolin M, Giugliani R, Felix TM. Genetics of homocysteine metabolism and associated disorders. Brazilian Journal of Medical Biological Research, 2010; 43(1):1-7

36. Tripathi P. Homocysteine-the hidden factor and cardiovascular disease: cause or effect? Analytical Biochemistry, 2015; 4(2):4

37. Danjuma N, Zezi AU, Abdu-Aguye J, Prevelence and prognosis of cardiovascular accident in Zaria, Kaduna State, Nigeria. Journal of Pharmacology and Biological Research, 2005; 2(2):169-173

38. Owolabi MO, Akarolo-Anthony S, Akinyemi R, Arnett D, Gebregziabher M, Jenkins C et al, The burden of stroke in Africa: a glance at the present and a glimpse into the future. Cardiovascular Journal of Africa, 2017; 26(3):123-133
39. Flemming FA., Ogunfunmilade TA, Carmel R, Serum vitamin $\mathrm{B}_{12}$ levels and vitamin $\mathrm{B}_{12}$ binding proteins of serum and saliva of healthy nigerians and europeans. American Journal of Clinical Nutrition, 1978; 31(10):1732-1738

40. Refsum H, Fiskerstrand T, Guttormson AB, Ueland PM, Assessment of homocysteine status. J Inherited Metabolic Disorders, 1997; 20:296-294

41. Refsum H, Nurk E, Smith AD, Ueland PM, Gjesdal CG, Bjelland I, Vollset SE, The Hordaland homocysteine study: Community-based study of homocysteine, its determinants, and associations with disease. Journal of Nutrition, 2006; 136(6):1731-1740

42. Thambyrajah J, Landray M J., McGlynn FJ, Townend JN, Does folic acid decrease plasma homocysteine, improve endothelial function in patients with pre-dialysis renal failure. Circulation, 2000; 102(8):871-875

43. Jaques PF, Selhub J, Boston AG, Wilson PW, Rosenberg IH, The effect of folic acid fortification on plasma folate and total homocysteine concentrations. New England Journal of Medicine, 1999; 340:1449-1454

44. Homocysteine Lowering Trialists Collaboration, Lowering blood homocysteine with folic acid based supplements: meta-analysis of randomised trials. British Medical Journal, 1998; 316 (7135):894-898

45. Lim U, Cassano PA, Homocysteine and blood pressure in the Third National Health and Nutrition Examination Survey, 1988-1994. American Journal of Epidemiology, 2002; 156(12):1105-1113.

\section{Author Contribution:}

$\mathrm{I}^{\text {st }}$ Author: Conceptualization and design of study, literature search and review, field work and data collection, laboratory analysis with help of laboratory scientists, validation of data collected and data analysis, article write-up and review to its final version and access to data.

$2^{\text {nd }}$ Author: Modification of topic, design of study, supervision of literature review, supervised field work and data collection, validation of data collected, reviewed manuscript to its final version.

$3^{\text {rd }}$ Author: Design of study, supervision of literature review, supervised field work and data collection, validation of data collected, reviewed manuscript to its final version.

$4^{\text {th }}$ Author: Design of study, supervision of literature review, supervised field work and Data collection, validation of data collected and data Analysis, reviewed manuscript to its final version.

Funding 'There was no specific grant from any funding agency in the public, commercial or not-for-profit sectors.' However, Emzor Pharmaceutical Industries Limited, Lagos, Nigeria supplied Folic acid and its placebo and Micro Nova Pharmaceuticals Limited, Nigeria supplied anti-hypertensive drugs.

Disclaimer The views expressed are those of the author (s) and not necessarily those of MicroNova Pharmaceuticals Ltd, Nigeria or Emzor Pharmaceutical Industries Limited, Lagos, Nigeria.

Ethical approval The study was approved by Health Research Ethical Committee (HREC), Ministry of Health, Kaduna (ref: $\mathrm{MOH} / \mathrm{ADM} / 744 / \mathrm{VOL} .1 / 369)$ and all participants gave written informed consent. 